This is a post-print version of the article, published as:

Crookes, D.J., 2017. Does a reduction in the price of rhino horn prevent poaching? Journal for Nature Conservation 39: 73-82. URL: https://doi.org/10.1016/j.jnc.2017.07.008

\title{
Does a reduction in the price of rhino horn prevent poaching?
}

Douglas J. Crookes ${ }^{\mathrm{a}^{*}}$

${ }^{a}$ Department of Economics, University of Pretoria, Hatfield, South Africa

* Address for correspondence: Douglas Crookes, Department of Economics, Private Bag X20, Hatfield, Pretoria, 0028, South Africa; email: dcrookes@outlook.com

\begin{abstract}
Rhino poaching around the world has increased inordinately, to the extent that concerns exist over the possible survival of the species. An open access rhino poaching model is developed for South African rhino. The model is a hybrid dynamical model, as both a system dynamics model as well as a Bayesian network model are developed. The system dynamics model is used to estimate the unknown parameter values (through optimisation) and also to determine the intervals for the parameters. These intervals are then used in the Bayesian Belief Network model to assess uncertainty. Hybrid approaches improve the ability to validate models compared with conventional modelling. The resultant model indicates that reducing the price of rhino horn would not be effective at curbing poaching, unless poacher costs are also increased. However, increasing poacher costs is not a realistic policy option since these costs are largely beyond the control of decision-makers. The insensitivity of price to poaching effort has implications for methods proposed to reduce the value of rhinos, such as introducing synthetic rhino horn and the de-horning of rhinos.
\end{abstract}

Keywords: Open access; system dynamics; Bayesian network; Ceratotherium; Diceros

1

Introduction

Poaching of African rhino have increased immensely in recent years, threatening the very survival of the species. Data from CITES' 16th meeting of the Conference of the Parties in Bangkok, Thailand in 2013 (CITES 2013a, 2013b) paints a grim picture of the situation. Poaching has grown, on average, by $52 \%$ per annum for the period 2006-2012. One reason for the high incidence of poaching in South Africa is the relative abundance of rhinos in that country. The vast majority $(90 \%)$ of all African rhino are poached from South Africa. At the end of 2012, the African white rhino (Ceratotherium simum) population comprised 20405 individuals and the African black rhino (Diceros bicornis) comprised 5 055 individuals. South Africa's rhino population comprises approximately $93 \%$ and $40 \%$ of the total white and black rhino populations, respectively. Another reason for the high poaching incidence in South Africa is the vast areas under conservation. The Kruger National Park alone spans $20000 \mathrm{~km}^{2}$, which is roughly the size of Wales (Markham 2014). This makes patrolling very difficult. In spite of 
these alarming statistics pointing to a major poaching problem, very little modelling work has been conducted to understand wildlife/poaching dynamics in South Africa.

A number of approaches have been proposed to lower the price of rhino horn, arguing that this would eliminate the incentives to poach rhinos. These include the introduction of synthetic rhino horn as a substitute for real horn (Ball 2015), de-horning of rhinos (Milner-Gulland 1999). Other approaches include a shock stockpile offload, episodic auctions, incremental releases of small batches, or through a closely regulated cross-continental legalised supply chain. The argument is that these would devalue the rhino and reduce the incentive to poach. Lee and Roberts (2016) assess the effect of de-horning using game theory. They found that only if all rhinos were dehorned would the incentive to poach be reduced. However, this was a theoretical analysis and the effect of a lower price for rhino horn on poaching has not been assessed using actual poaching data. This research study examines the effect of a decreasing in the price of rhino (either through introducing synthetic rhino horn, dehorning or any other methods) on poaching behaviour, using data for South African rhino.

A modelling approach that has gained increased prominence in modelling wildlife systems is system dynamics modelling (e.g. Ford 1999). There are, however, few applications to rhino. Swart et al. (1990) developed a model for black rhino in South Africa which mainly focusses on fecundity and population dynamics. Although it was primarily used to determine optimal offtake, it was nonetheless historic as it was able to predict a recovery of black rhino to a genetically viable population of approximately 2000 individuals over 30 years, which is more or less the situation prevalent today. Crookes and Blignaut (2015) developed a system dynamics model for market demand that considers rhino populations, game farms and consumer demand. The model did not, however, explicitly model poaching behaviour. Crookes and Blignaut (2016) found that policies aimed at the management of protected areas were more likely to be effective in the management of rhinos. Therefore, this study aims to examine in greater depth the conditions under which rhino populations may persist, by looking at a number of policy tools that aim at influencing poacher behaviour. These policy tools include: policies that affect the price of rhino horn, the costs of poaching, and enforcement policy tools such as the policies that influence the probability that a poacher is detected and convicted, and the magnitude of the fine.

It is important to take uncertainty into account when modelling and understanding the dynamics of ecological and economic systems (Bunnefeld et al. 2011). This study applies two methods to assess parameter uncertainty in the data. First, Monte Carlo simulation is used to define the interval boundaries of the study. This is conducted in the system dynamics software Vensim (Eberlein and Peterson 1994). Second, these interval boundaries are used in a Bayesian Belief Network (BBN) model to assess the effect of parameter uncertainty on the outputs of the model. The BBN model is constructed using the software package Netica (Norsys Software Corp. 1997). In this sense, although the two models are distinct, data from the systems model is used as input into the BBN model, and vice versa. The model is, therefore, a hybrid dynamical system, as both continuous and discrete dynamic behaviour is captured (Goebel et al. 2009). The system dynamics model employs continuous (feedback) dynamics, and the BBN model incorporates discrete probability nodes. In the next section the hybrid SD/BBN model is presented along with the steps in the modelling process. 


\subsection{System dynamics model}

System dynamics modelling is an approach that simulate the behaviour of complex systems over time, with feedback loops and time delays characterising the interactions of the system. It is important to model feedbacks in conservation systems given the propensity of these systems toward counterintuitive behaviour (Larrosa et al. 2016). Equations (1) and (2) indicate the feedback dynamics of the system, which follows a predator-prey specification. These dynamics could be analysed in an excel spreadsheet. However, there are a number of reasons for analysing these two equations in a system dynamics modelling platform such as Vensim. First, it provides a visual display of the interactions between the different elements in the system which is called a stock flow diagram. Second, it enables the comparison of the model with actual data and facilitates calibration of the model with actual data. Statistical tests may then be performed on goodness of fit. Thirdly, a number of validation techniques may be employed on the model, for example dimensional (unit) consistency tests, behaviour reproduction and sensitivity analysis. It would not be possible to conduct the full range of validation tests on a spreadsheet model.

The system dynamics modelling framework makes it possible for the model to be interrogated in order to answer "what if"-type questions (Butterworth et al. 2015). This is done in two ways. First, the Synthesim ${ }^{\mathrm{TM}}$ mode enables real-time analysis of the effects of changes in the different parameters on the model. This enables one to evaluate different ranges in parameters without having to enter values discretely. Second, Monte Carlo simulation may be used to conduct a sensitivity analysis on a range of management parameters, such as the probability of detection and conviction, the magnitude of the penalty, the poaching costs and the price of rhino horn on poaching behaviour, and ultimately what the impact would be on the persistence of rhino populations. These two approaches are fairly novel in system dynamics applications focussed on wildlife population modelling (see Crookes 2016). Last, only model results need to be exported to excel for further analysis.

The Gordon-Schaefer model is not the only framework used by system dynamics modellers in wildlife population modelling. In South Africa, Swart et al. (1990) use an age-structured density-dependent model for rhino. Although the Gordon-Schaefer model is common in the wildlife literature (e.g. Leclerc et al. 2015), its suitability will be assessed by examining how well it is able to replicate the historical data. In the next section the Bayesian Belief Network framework is presented.

\subsection{Bayesian Belief Network model}

BBNs and SD modelling are both decision-support systems (DSS) used to model uncertainty (Cain 2011). Netica is a probabilistic graphical model that uses the junction tree algorithm to obtain posterior distributions over hidden variables (Korb \& Nicholson 2010). It uses Bayes' rule for updating the distribution over parameters from the prior to the posterior distribution. 
Vensim and Netica are similar in that both are used to model complex systems, and both are examples of decision support tools. Vensim uses Monte Carlo simulation by means of the Latin Hypercube sampling methodology. But the Bayesian inference is a more exact method of estimating uncertainty than Monte Carlo sampling (Cain 2011). Also, in a BBN model, a range of prior distributions may be defined and its effect on the posterior distribution assessed. Netica is used for undirected networks and it is therefore not possible to include feedback in the model.

The approach adopted here is to use Monte Carlo simulation in the system dynamics package to define the boundaries of the different parameters, which are then converted into intervals in the Bayesian Belief Network (BBN) model. A steady state version of the model was then constructed for use in the $B B N$. The results of the BBN model were used to further validate the model, and also used for policy simulations.

\subsection{Steps in the modelling process}

This section presents the steps in the modelling process, with reference to the framework proposed by De Wit and Crookes (2013). These steps are based on a more generic systems analysis framework suitable for a variety of model types and draw from the natural resource management literature. The steps are the following:

1. Model conceptualisation - model and subcomponents are described and discussed

2. Model quantification - important empirical relationships underpinning the model are presented

3. Model evaluation - model validation is presented on the key relationships in the model

4. Model use - the model is used to estimate the value of unknown parameters and also to answer the research question

5. Improving system performance - revisit some of the key assumptions of the model and make recommendations on the way forward

\subsubsection{Model conceptualisation}

The model is based on two strands of literature: predator-prey literature and open-access fisheries literature.

A predator-prey model is developed using system dynamics modelling employing a Gordon-Schaefer fisheries model. This model is based on Nobel laureate Gary Becker's theory of crime and punishment (Becker 1968). It is applied to both fisheries (Mazany et al. 1989) and rhino (Milner-Gulland \& LeaderWilliams 1992) where poaching effort is not only a function of costs and prices, but also of various enforcement parameters. A similar model was developed for an abalone fishery subject to illegal exploitation (Crookes 2016). Despite featuring strongly in theoretical or teaching presentations of system dynamics (e.g. Venkat 2005), applications of predator-prey models to natural resources are not all that common. A possible reason for this is that the Gordon-Schaefer model can be developed 
in spreadsheets which are accessible to most people and do not require advanced modelling software to implement. One notable exception to this relatively scarce application to natural resources is Uehara (2013), who developed a predator-prey model based on the Easter Island model of Brander and Taylor (1998). His motive for using system dynamics modelling is "the complexity of the model" (Uehara 2013:375). The next section presents the enforcement component of the model.

The model is also based on the open-access fisheries literature (e.g. Wilen 1976; Bjørndal \& Conrad 1987; Opsomer \& Conrad 1994), using a rhino horn poaching model by Milner-Gulland and LeaderWilliams (1992). The model was originally developed for the Luangwa valley, Zambia, but the input parameters were adapted to match historical data from the South African rhino horn trade. In the next section, important empirical relationships underpinning the model are presented.

\subsubsection{Model quantification}

Following Milner-Gulland and Leader-Williams (1992), the poacher's profit maximisation function is:

$$
\underset{E}{\max \pi}(h)=p h-c E-\theta F
$$

Where $p$ is the price of rhino horn, $c$ is the unit cost of poaching, $\theta$ is the coefficient of detection and conviction, and $F$ is the penalty, and $E$ is the poaching effort, measured in number of expeditions. Harvest is assumed to be a linear function of poaching effort:

$$
h_{t}=m q E_{t} x_{t}
$$

Where $q$ is the catchability coefficient and $x$ is the rhino population, and $m$ is a mortality coefficient relating efforts and stocks to harvests (Crookes 2016).

The fine $F$ is a flat rate and includes the confiscation of the rhino horn, since monitoring data indicates that each group of poachers only captures one horn on each expedition:

$$
F=f+p
$$

In the case of rhino poaching in South Africa, the penalty is a prison sentence, but in order to obtain a monetary value for $f$, the number of years the poacher spends in jail is multiplied by the average annual wage rate (see supplementary material).

The coefficient of detection and conviction is a function of effort:

$$
\theta=b E \text {, where } 0<b<1
$$

Where $b$ is the probability of detection. The rhino population growth follows an adapted logistic formulation to take into consideration a non-linear response to density:

$$
f(x)=r x\left(1-\left[\frac{x}{k}\right]^{z}\right)-h
$$


This appears to be the most realistic formulation of rhino population dynamics, following an evaluation of models by Cromsigt et al. (2002). In order to transform the equilibrium model into a dynamic model, we write the dynamics of poacher effort as follows:

$$
E_{t+1}=E_{t}+n\left(p q E_{t} x_{t}-c E_{t}-\theta(f+p)\right)
$$

Equation 6 states that poaching effort increases or decreases depending on revenues pq $E_{t} x_{t}$, costs $c E_{t}$, and levels of enforcement $\theta(f+p)$, and a parameter $n$, which is an adjustment parameter determining the time frame over which effort responds to changes in profits and enforcement. Substituting $n^{\prime}=n p$ and $\theta=b E$ and re-arranging gives the following:

$$
E_{t+1}=E_{t}+n^{\prime} E_{t}\left(q x_{t}-\frac{c}{p}-\frac{b(f+p)}{p}\right)
$$

The terms in brackets indicate that poaching effort is an increasing function of the price of rhino horn, and a decreasing function of the cost price ratio and the probability of detection $b$ and the fine $f$.

Similarly, rhino populations may also be re-written in dynamic form by incorporating equations (2) and (5). Rhino population dynamics are then as follows:

$$
x_{t+1}=x_{t}+s x_{t}\left(a-d x_{t}^{z}-m q E_{t}\right)
$$

Where

$$
a=r \text { and } d=\frac{a}{k^{z}}
$$

The parameters $s$ allows for delays in the adjustment of populations to both growth and harvests, but in the basic model $s=1$.

\subsubsection{Model validation}

Model validation is discussed in the supplementary material (S.1). 


\subsection{System dynamics model}

\subsubsection{Stock flow diagram}

A stock flow diagram shows the interactions between the various components in the model (Figure 1). A box represents a stock variable, which accumulates or decreases depending on the flow variables coming into or leaving it. Other variables in the system include constants or other auxilary variables represented by an equation. This relatively simple model captures some fairly complex dynamic behaviour.

Figure 1 indicates that poaching effort may either increase or decrease depending on a number of parameters. Poaching effort increases due to an increase in the net birth rate of rhinos, and decreases based on the poacher's cost price ratio and the penalty for infringement, which is a function of the fine ( $f$ ) and the probability of detecton and conviction (b).

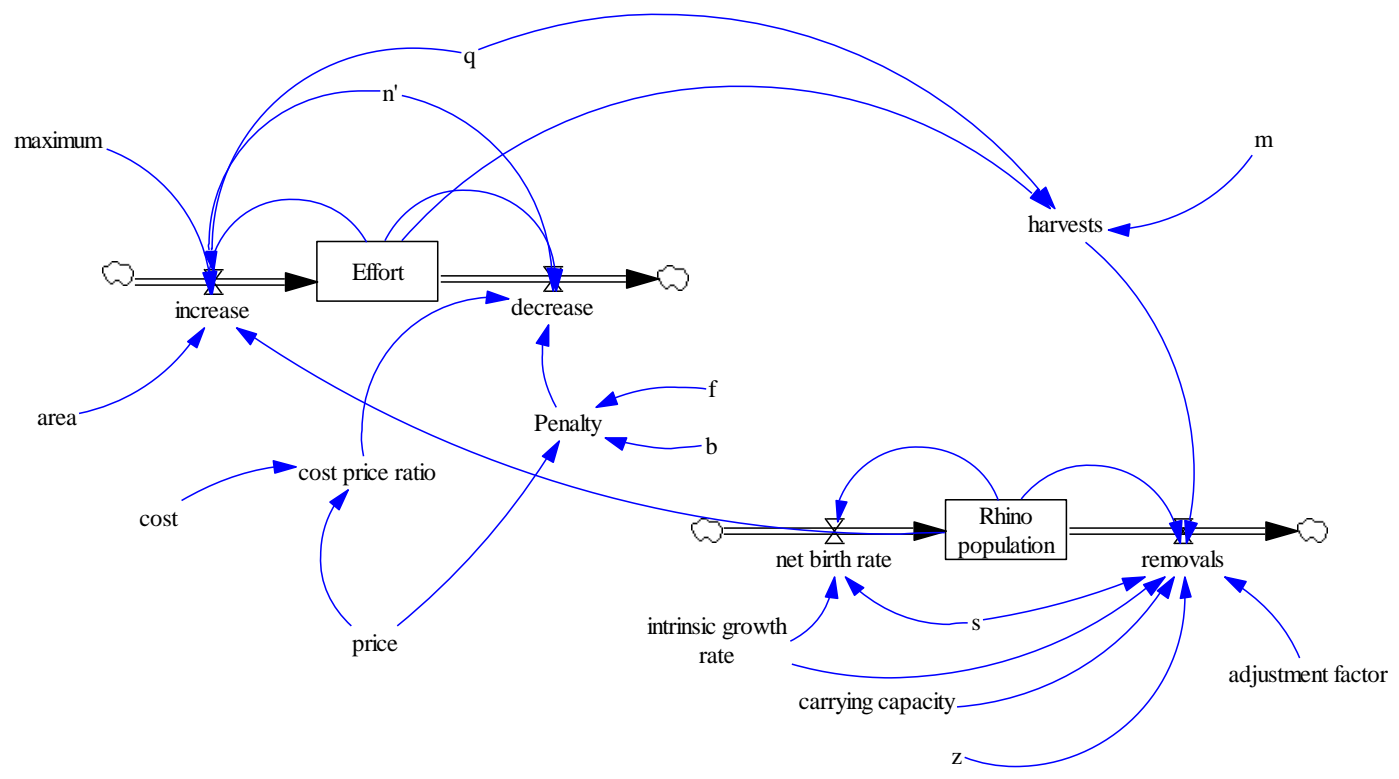

Figure $1 \quad$ Stock flow diagram for poaching model 


\subsubsection{Model calibration}

Baseline parameter values were obtained from a range of literature sources (see Supplementary Material S.2) while others were derived from model simulations. The unknown parameters, namely the intrinsic growth rate $r$ and the adjustment parameter $n^{\prime}$, were estimated using optimisation so that the best fit with the historical data was achieved. Figure 2A (rhino dynamics) and Figure 2B (effort dynamics) indicate the results of this fit.
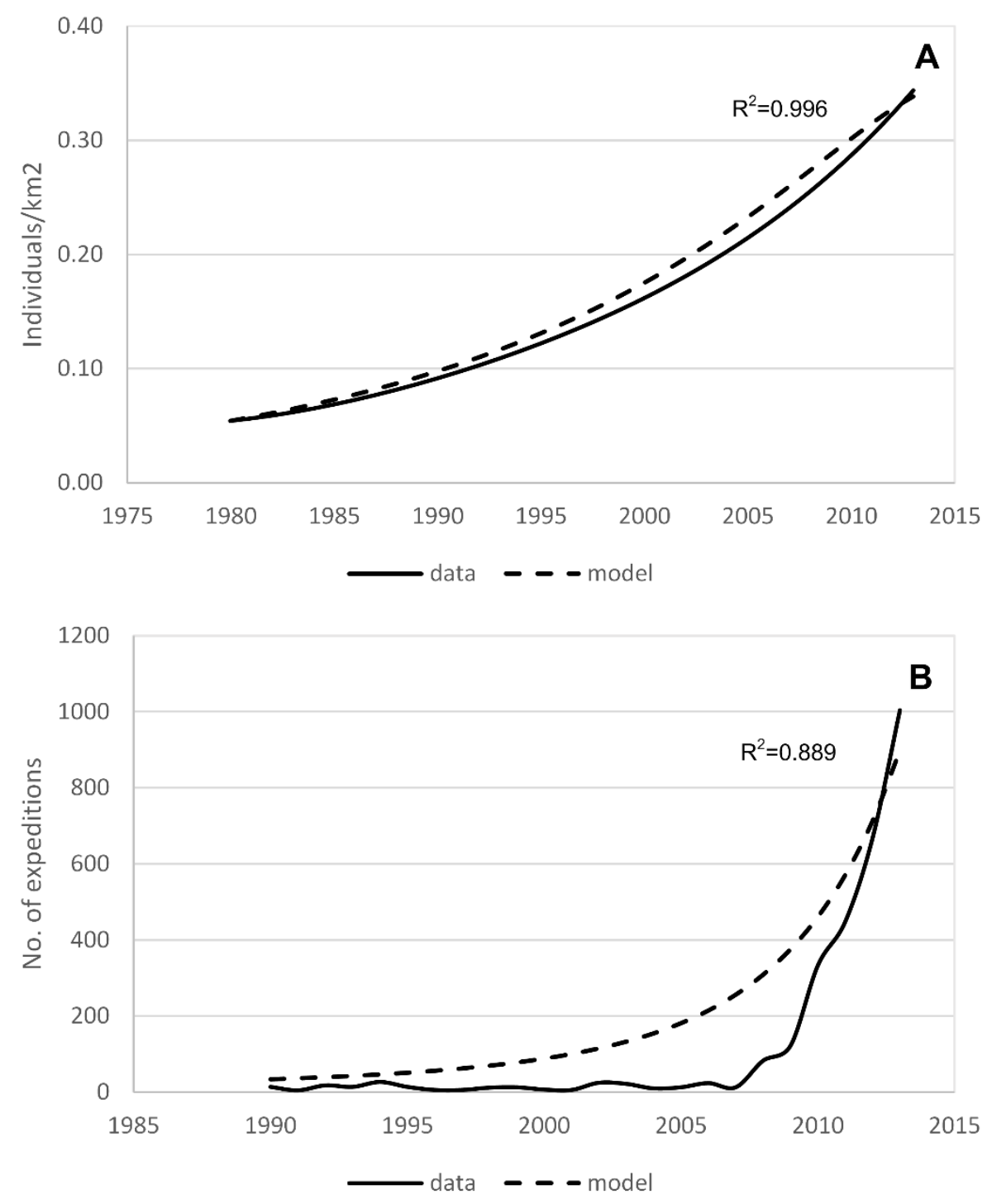

Figure 2A Rhino population dynamics, 1980-2013 and Figure 2B Effort dynamics, 1990-2013

The results show that the rhino population model provides a slightly better fit $\left(R^{2}=0.996\right)$ than the effort data's fit with the historical data $\left(R^{2}=0.889\right)$. Both therefore provide a reasonable fit with the historical data. While the effort function does not capture the long lag before effort rises, it is not necessary for a system dynamics model to replicate the exact behaviour of the system, but rather that 
the model captures the major "dynamic patterns" of the model (Saysel \& Barlas 2001). This is indeed satisfied in the present model. Although $\mathrm{R}^{2}$ values are not the only criteria for assessing the goodness of fit, the results nonetheless suggest that the model is suitable for replicating the system and the Gordon Schaefer model provides a reasonable proxy for exploring rhino population dynamics in South Africa.

\subsubsection{Model parameters}

Table 1 summarises the parameters used in the model, including those that gave the best fit to the data. The parameters highlight two surprising results. The first relates to the value of the intrinsic growth rate for rhino populations. Hall-Martin (1986) estimates a value of the intrinsic growth rate of $0.096\left(r_{\max }=0.16\right)$ for the black rhino population at Addo Elephant National Park. This is slightly higher than their earlier estimates of $0.09\left(r_{\max }=0.15\right)$ for the Kruger National Park's rhino population. This model does not model black and white rhinos separately as both species are hunted indiscriminately. The value for $r$ used in the study is therefore a composite value and is estimated based on the best fit of the rhino population to the historical data. A similar approach was pursued by Cromsigt et al. (2002) for black rhino populations in Hluhluwe-Umfolozi and Mkuzi Game Reserves, South Africa. Their estimates for $r$ (for the logistic and Fowler models) ranged between 0.06 and 0.1 , with the model that gave the best fit at the upper end of the range $(r=0.1)$.

Table 1 Parameters used in the model

\begin{tabular}{|l|l|l|l|l|}
\hline Parameter & Symbol & Value & Units & Description \\
\hline Cost $^{1}$ & $\mathrm{c}$ & 36.36 & dollars/expeditions & Cost of poaching \\
\hline $\begin{array}{l}\text { Catchability } \\
\text { coefficient }^{1}\end{array}$ & $\mathrm{q}$ & $\begin{array}{l}4.48366 \mathrm{e}- \\
005\end{array}$ & 1/expeditions & $\begin{array}{l}\text { Ease with which rhinos may be } \\
\text { poached }\end{array}$ \\
\hline $\begin{array}{l}\text { Probability of } \\
\text { detection }^{1}\end{array}$ & $\mathrm{~b}$ & 0.007 & rhino/expeditions & $\begin{array}{l}\text { Likelihood of detection prior to a } \\
\text { poaching event }\end{array}$ \\
\hline $\begin{array}{l}\text { Adjustment } \\
\text { coefficient }^{2}\end{array}$ & $\mathrm{n}$ ' & 0.275 & $\begin{array}{l}\text { expeditions/rhino } \\
\text { /year }\end{array}$ & $\begin{array}{l}\text { Rate at which poaching effort } \\
\text { responds to changes in profits and } \\
\text { enforcement }\end{array}$ \\
\hline Price $^{1}$ & $\mathrm{p}$ & 15000 & dollars/rhino & Price of rhino horn \\
\hline $\begin{array}{l}\text { Fine } \\
\text { coefficient }^{1}\end{array}$ & $\mathrm{f}$ & 2695.53 & dollars/rhino & Monetary value of penalty \\
\hline $\begin{array}{l}\text { Fowler } \\
\text { (curvilinear) } \\
\text { factor }^{3}\end{array}$ & $\mathrm{z}$ & 7 & Dimensionless & Density dependent term \\
\hline $\begin{array}{l}\text { Carrying } \\
\text { capacity }^{3}\end{array}$ & $\mathrm{~K}$ & 0.4 & rhino/km2 & Maximum population level \\
\hline $\begin{array}{l}\text { Intrinsic growth } \\
\text { rate }^{2}\end{array}$ & $\mathrm{r}$ & 0.061 & Dimensionless & Rhino population growth rate \\
\hline $\begin{array}{l}\text { Mortality } \\
\text { coefficient }^{1}\end{array}$ & $\mathrm{~m}$ & 1 & Dimensionless & $\begin{array}{l}\text { Extent to which populations } \\
\text { respond to harvests }\end{array}$ \\
\hline
\end{tabular}

Source: ${ }^{1}$ Own calc=see supplementary material; ${ }^{2}$ Model=Value that gave best fit of model with historical data (i.e. that maximised $\mathrm{R}^{2}$ ); ${ }^{3}$ Milner-Gulland \& Leader-Williams (1992) 
The literature does, however, show wide disparities between different populations even in close proximity to each other. For example, Hitchins and Anderson (1983) found an $r$ of 0.053 for the Hlulhluwe black rhino population, and 0.11 for Umfolozi populations, a figure more than twice as great. The present study's estimate for $r$ of 0.061 suggest that rhino populations on the whole are growing at the lower end of the range of value estimates from the literature rather than at the upper end. This has important implications for rhino sustainability modelling.

A second surprising result is the low probabilities of detection prior to a poaching event $(b)$ observed in the study. This is in spite of apparent increases in enforcement effort and severity of sentences. In Lwangwa valley (Zambia), Milner-Gulland and Leader-Williams (1992) observed a probability of detection and sentencing of 0.05 . In this analysis, the literature from South Africa indicates a probability of detection and conviction of 0.007 (Table 1). Furthermore, this value has remained relatively stable over the past five years (see supplementary material). A reason for the low and invariable probability of detection is most likely because increases in enforcement effort have merely served to keep pace with increases in poaching effort, and have therefore not managed to increase to a level where the probability of detection increases.

In most bioeconomic analyses, the adjustment parameter $n^{\prime}$ is unknown and needs to be simulated using sensitivity analysis. A novel feature of this model was that it was possible to estimate a value for this parameter using the fit of the model to the existing historical data. The adjustment parameter normally measures the sensitivity of effort in time $t+1$ to profits, and although this is technically correct, only indirectly so. In the first instance the adjustment parameter measures the elasticity of effort with respect to rhino abundance. According to the model, it takes a change in rhino abundance of 3.64 individuals per year to change the number of poaching expeditions by 1 . Rhino abundance, in turn, is a function of the price of rhino horn, expedition costs, the magnitude of the fine, the probability of detection, and the catchability coefficient. This model outcome holds under current conditions of increasing rhino abundance and increasing levels of poaching, and therefore predicts that should rhino populations begin to decline then poaching effort would also decline, but that this would be insufficient to prevent local extinctions of rhino populations.

\subsubsection{Simulation results}

The model predicts that, under current conditions, local extinction of rhino populations will occur over the next 20 years or so. This is in accordance with the findings of both Crookes and Blignaut (2015) and Di Minin et al. (2015).

It is clear from Equation 1 that the variables which affect poaching effort are the cost price ratio, the adjustment coefficient $n^{\prime}$, the price of rhino horn, the probability of detection and prosecution $(b)$, and the magnitude of the fine coefficient $f$. Changes in poaching effort, on the other hand, affect the dynamics of rhino populations (Equation 2). The question then is whether there are values for the enforcement parameters that would result in sustainable rhino populations? In order to answer this 
question, Monte Carlo simulations are conducted on the key policy variables in order to assess the effectiveness of different policies.

Monte Carlo simulations were conducted on the following key policy variables in the model - costs, prices, the fine parameter $f$ and the probability of detection prior to a poaching event $b$. A uniform distribution is used to generate a random sample across a range of values that are not weighted in any way. The probability density function of the uniform distribution is the following:

$$
f(w)=\frac{1}{h-g} \text { for } g \leq w \leq h, 0 \text { otherwise }
$$

The first and second set of simulations assess the effect of varying different combinations of policy parameters. In the first set of simulations the enforcement parameters $b \sim U(\bullet, 0.3)$ and $f \sim$ $U(\bullet, 100000)$ are varied, while in the second set of simulations the profitability parameter $\mathrm{c}=\mathrm{U}(\bullet, 5000)$ and $\mathrm{p}=\mathrm{U}(1000, \bullet)$ are varied, where $\bullet$ is the value of the baseline parameter (see Table 2 ). The first scenario, therefore, simulates the effect of increasing the probability of detection and the magnitude of the fine, for various combinations of $b$ and $f$; the second scenario simulates the effect of increasing costs and decreasing prices. All simulations were run for an ensemble of 200 realisations, giving continuous values for $p, c, b$ and $f$. The outcome variable was rhino abundance. The results are plotted on bubble charts where the size of the bubble indicates rhino abundance at the end of the simulation (Figure 3).

Increasing the probability of detection and the magnitude of the fine increases the sustainability of rhino populations (increasing $b$ and $f$-see Figure $3 \mathrm{~A}$ ). This supports the assertion that command and control measures are important in rhino management in South Africa. However, reducing the price of rhino horn does not, for the most part, improve sustainability of rhinos (see Figure 3B). The cost of rhino poaching would have to increase and the price of rhino horn reduce dramatically for rhinosto persist.

\subsection{Bayesian Belief Network model}

The Bayesian Belief Network (BBN) model produces similar results than the system dynamics model. Under the baseline scenario, the probability that effort would increase compared with current (2013) levels is 29 percent (see Figure 4A). Reducing the price of rhino horn to $\$ 3000$ per rhino only reduced the probability that effort would increase by 7 percent, to 22 percent (see Figure 4B). On the other hand, increasing the probability of detection to 0.4 , and increasing the magnitude of the fine to $\$ 60000$ per rhino significantly reduces the probability of effort increasing above current levels. The probability of effort increasing drops by more than half, from 29 percent to 13 percent (see Figure 4C). The advantage of BBN models is that they improve decision-makers' understanding of the ecological and economic system, while at the same time enabling them to come to their own conclusions based on that knowledge (Cain 2011). The results, therefore, indicate that there is still a (small) probability that effort will increase even if a rigid enforcement and prosecution strategy is pursued. Furthermore, there is also a (small) probability that a price reduction strategy will be effective. This is due to 
uncertainty in the parameters in the model. It is left to the decision-makers to decide whether or not these probabilities are small enough.
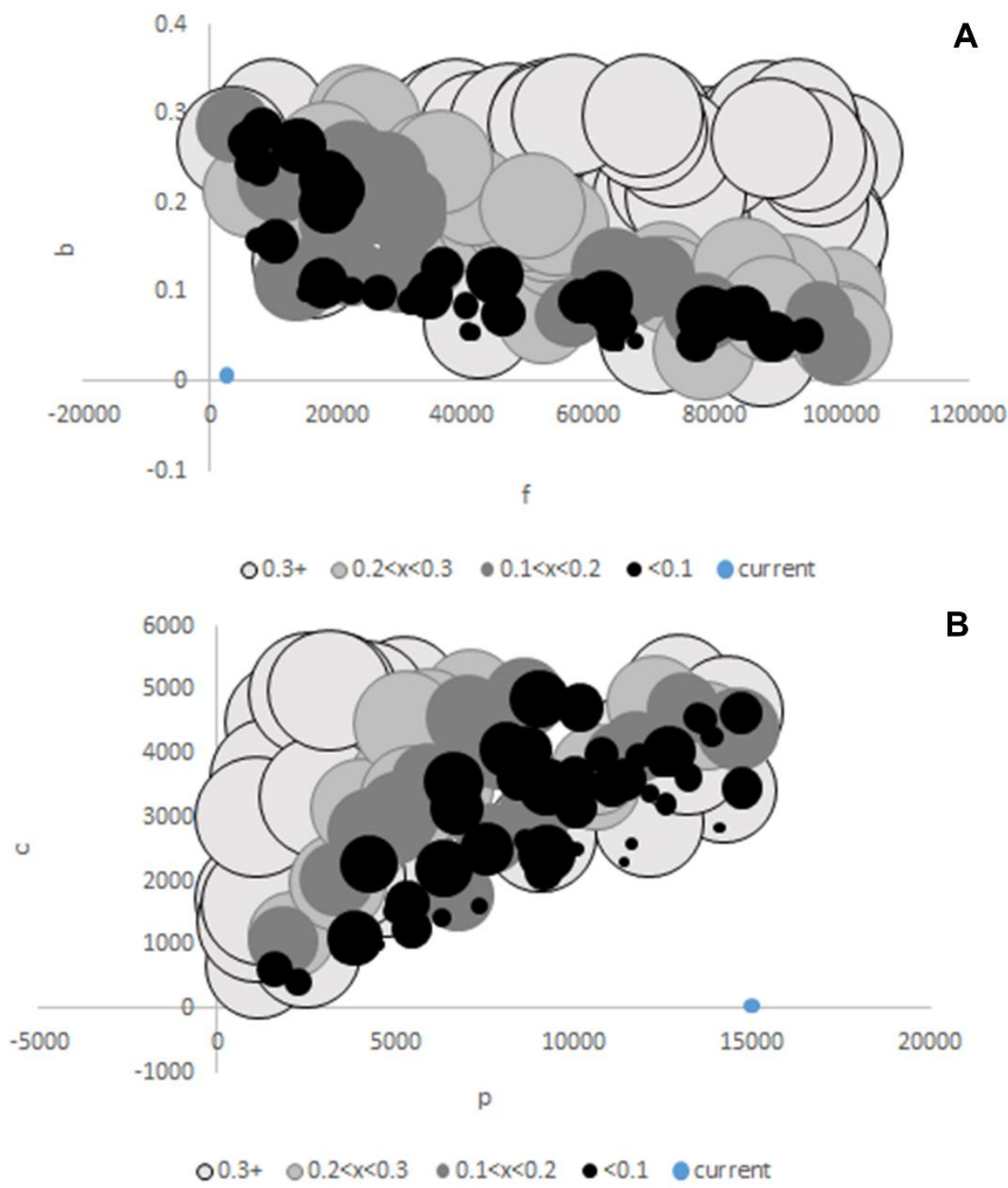

\section{Figure $3 \quad$ Effects of varying policy parameters}

Bubble plots of enforcement parameters (Figure 3A), and profitability parameters (Figure 3B). The size of the bubbles and the shading indicate the relative magnitude of rhino abundance at the end of the simulation period. Four categories are used (represented by the different shading), indicating different levels of rhino abundance (less than $0.1 \mathrm{rhino} / \mathrm{km}^{2}$ - darkest shading through to greater than $0.3 \mathrm{rhino} / \mathrm{km}^{2}$ - lightest shading). The blank space (bottom left in Fig. $3 \mathrm{~A}$ and bottom right in Fig. $3 \mathrm{~B}$ ) indicate no viable populations for the given values of the policy parameters. The small blue circles indicate the baseline values, showing that under prevailing conditions rhino populations will not persist (circles in the white zone of the graph). The axes of parameters $b$, $f, c$ and $p$ contain negative values because of the size of the bubbles. The nuclei of the bubbles, representing the value of the parameters, are all positive. 
A. Baseline

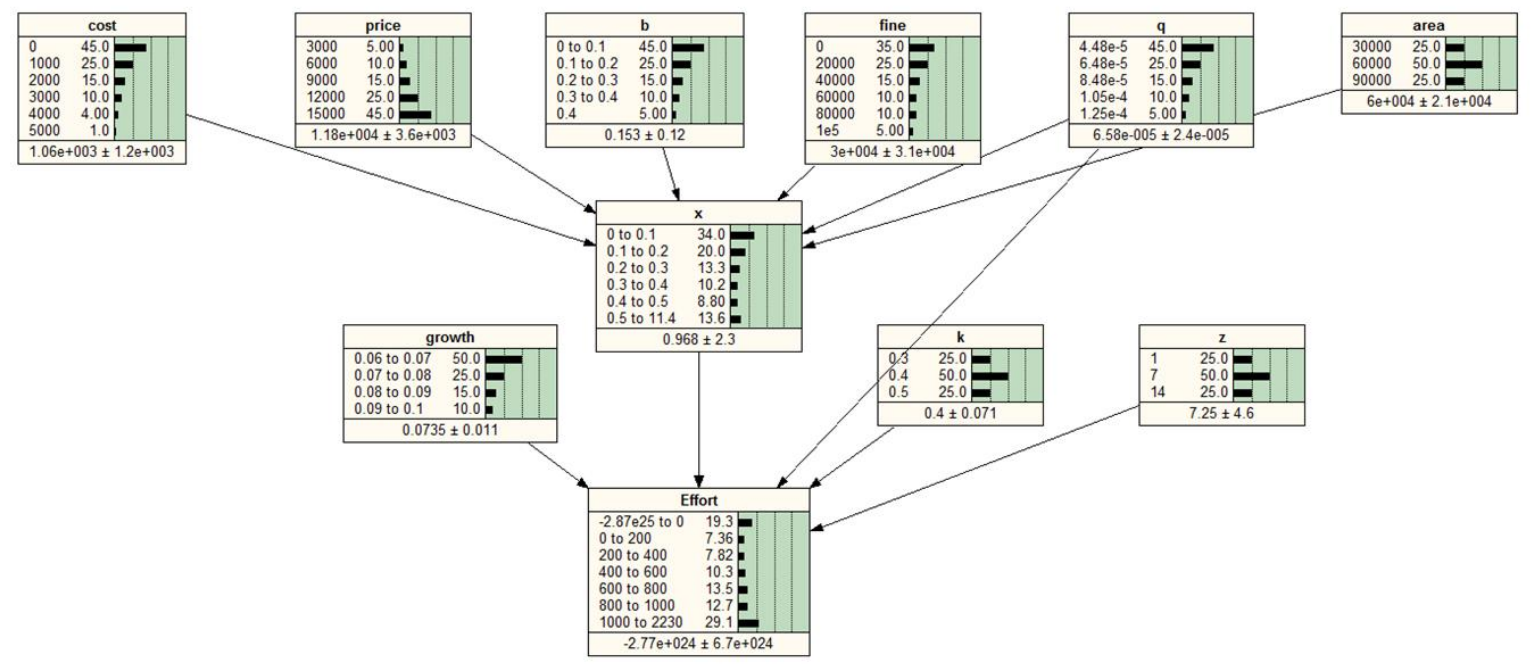

B. Reduction in rhino horn price

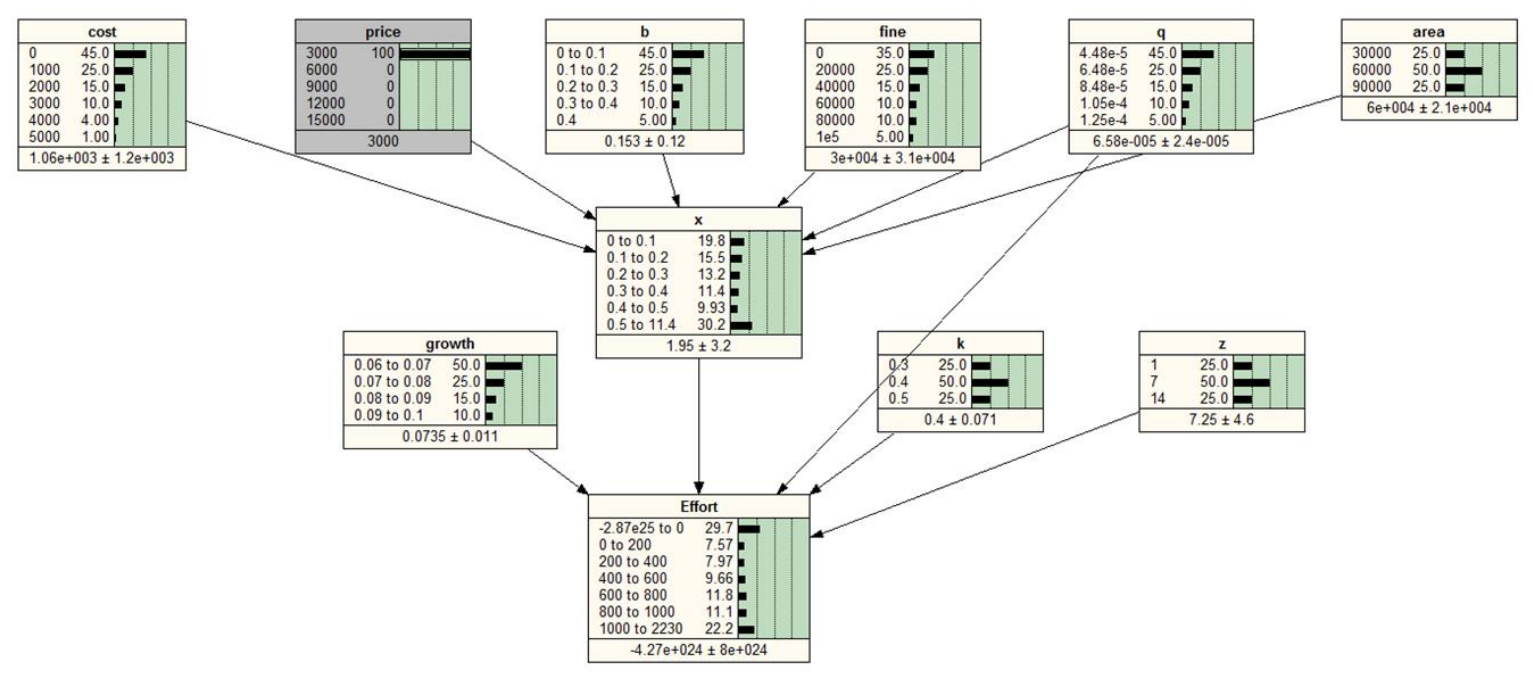

C. Increase in detection probability and fine

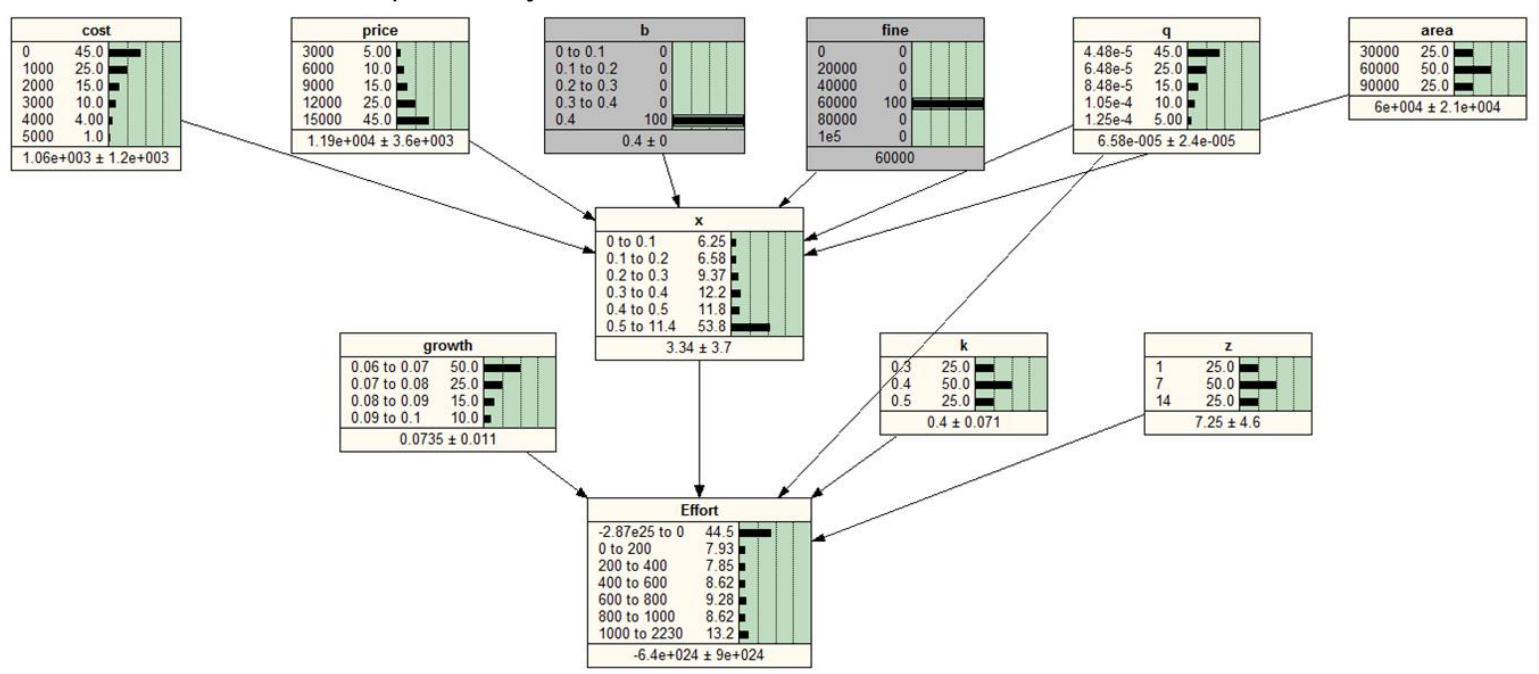

Figure 4 BBN model outputs: A. Baseline B. Reduction in rhino horn price (p) to $\$ 3000 / \mathrm{rhino}$ C. Increase in fine (f) to $\$ 60,000 /$ rhino and increase in probability of detection (b) to 0.4 
In order to assess whether or not the model is valid, it is first necessary to consider a key assumption of the model. For the model conditions to hold, the model requires that an open-access situation prevails with regards to rhino poaching. Do open-access conditions hold for rhino populations in South Africa? Milner-Gulland and Leader Williams (1992) and Bulte (2003) developed open-access models for black rhino in the Luangwa Valley, Zambia, so there is some precedent in the literature. According to Hall et al. (2008:78), "open-access exploitation assumes that hunters are subject to no restrictions, and has therefore been widely applied to species that are weakly protected by law, where hunting restrictions are weakly enforced and to poaching".

It is possible that these conditions exist in South Africa. Sixty percent of South Africa's rhinos are in one game reserve, Kruger National Park (KNP), and 75 percent of all rhinos are poached in KNP (DEA, 2014). The border with Mozambique is long, spanning $356 \mathrm{~km}$, making it difficult to patrol and highly 'porous' (Save the Rhino 2013). Approximately 80 percent of poachers at KNP come from Mozambique (Macleod 2014). The extremely low probability of detection and conviction observed in the sentencing records also points to an open-access situation prevailing in South Africa at present. Although efforts to curb poaching have increased, as have the number of arrests, the threat of poaching has continued to escalate as addressing the issue of poaching, according to South African Minster of Environment Affairs, "is not simple" (DEA 2014). The possible translocation of up to 500 rhino from KNP to 'safer' areas (Markham 2014) also points to the difficulties that park authorities are experiencing with protecting the rhino within their borders. Another reason why open-access conditions appear to hold for rhino populations in South Africa, is that the open-access model fits the historical data on rhino populations and effort reasonably well. This evidence strongly supports an open-access harvesting regime currently prevailing in South Africa.

The model passes all the validation tests discussed in the Supplementary material (S.1), as well as the sensitivity analysis test discussed in the results section. There is some surprising findings from the model, notably the low probabilities of detection and intrinsic growth rates, but the BBN model incorporates uncertainties and appears to substantiate the outcomes from the system dynamics model. The replication of the historical data is also adequate. The extreme conditions test, conducted using the BBN model, shows that sometimes parameters do take values that fall outside the bounds of realism. For example, under the baseline scenario, there is a 13.6 percent probability that rhino populations will exceed the population carrying capacity; furthermore, there is a 19.3 percent probability that poaching effort will be negative (see Figure 4A). This is clearly unrealistic and indicates that not all policy combinations are feasible.

The model passes most validation tests, with the exception of the extreme conditions test, which it fails 10-20 percent of the time. There are no clear standards in the system dynamics validation literature as to whether or not this is acceptable. The extreme conditions test in the SD literature is, for the most part, subjective. Barlas' (1996) recommends that "further research is needed to quantify and formalize such [extreme-condition testing] procedures, which are somewhat qualitative and semiformal at this stage" (p.192). The BBN/SD hybrid dynamical model developed here provides a means 
of quantifying the failure rate of the extreme conditions test. Although no absolute standard exists in the literature, it is argued that a 10-20 percent margin of error is acceptable, especially given that the BBN is assessing uncertainty in all the parameters of the model simultaneously.

Therefore, although there are some problems with the model, the overall conclusion from the validation exercise is that the model passes an adequate number of validation tests, and is therefore suitable for use. No model can be completely validated. However, our conclusion is that hybrid modelling approaches such as ours can actually provide better information about the validity of a model compared with conventional modelling alone.

In the next section, we consider the final step in the modelling process, namely improving system performance.

\section{5}

Improving system performance

In this final step of the modelling process, we revisit some of the key assumptions of the model and make recommendations on the way forward. First, the model assumes that poachers are a homogenous grouping. This is due to a lack of available disaggregation of poaching data. Further work is required to explore this assumption. Second, little mention is made of the on-the-ground institutional factors which may impinge on poaching. This is largely due to the changing nature of the institutional environment at present, and therefore would date the study. Institutional factors are, however, important and this aspect requires revisiting. Third, the behavioural aspects of the model, for example how poachers make decisions, are novel and require further exploration and validation.

System dynamics models are capable of modelling some very complex interactions between the parameters. However, this model is deliberately kept simple for two important reasons. The first is the paucity of data available to model more complex interactions between poachers and rhino populations. And the second is the need to ensure the defendbility of the model. Some system dynamics models have been criticised for not taking sufficient cognisance of "traditional" population modelling approaches (Butterworth et al. 2015). The model developed here is therefore firmly anchored in the population modelling literature.

The simplicity of the model and limitations on data availability, however also meant that the costs of enforcement are not taken into consideration in the model. Further work should consider optimal regulator strategies, such as the implications of increasing enforcement and the costs thereof. Finally, the model has elsewhere been applied in a range of contexts and for a number of species. Crookes and Blignaut (2016) model the global steel industry by coupling the predator prey formulation and system dynamics modelling, Crookes (2016) model South African abalone using a similar model, in addition to the present model that considers South African rhinos. Future work should consider a meta-analysis of studies, where lessons learnt from the different studies may be compared. 
Milner-Gullland (1993) and Crookes and Blignaut (2015) found that rhino horn consumers were insensitive to changes in the price of rhino horn, preferring to demand rhino horn regardless of the price. The present study finds that poachers also, are insensitive to changes in the price of rhino horn, continuing to hunt even if the price falls. The reason for this is unclear. One possible reason is the low cost of hunting, making hunting profitable even at low rhino horn prices. Another reason may be the low socioeconomic circumstances of hunters, being heavily reliant on revenues from poaching. Regardless, his finding is important, since it has implications for rhino horn management strategies that attempt to influence the price of rhino horn.

In particular, we consider the implications of price insensitivity on four management strategies proposed recently in response to poaching. These four policies were selected based on feedback from several role players. The four policies are: 1] the proposed introduction of synthetic rhino horn (Ball, 2015); 2] the de-horning of rhinos (Lee and Roberts 2016); 3] stockpiling and release on the market (Collins et al. 2017); and 4] A legalised trade in rhino horn (De Minin et al. 2015).

De-Horning seeks to de-value (reduce the price of) rhinos by removing the item of value from it, namely the horn. De-horning still leaves a stump, and our model shows that if the value of that stump exceeds $\$ 3,000$, then poaching effort is not reduced by any great margin. Approximately $1.2 \mathrm{kgs}$ remain on the stump after cropping (Eustace, 2012), and at an estimated selling price for poachers of $\$ 5,000 / \mathrm{kg}$ (Crookes and Blignaut 2016), the value of a stump is $\$ 6,000$. The conclusion is therefore that de-horning cannot reduces the value of rhino horn remaining on the animal sufficiently to advert poaching.

Synthetic rhino horn, stockpiling and release, and a legalised trade all work by the same principle. Flooding the market with horn (or synthetic alternatives) reduces the price, thereby (it is theorised), reducing the levels of poaching. However, since we show here that poaching is insensitive to price, none of these policies are likely to curb poaching.

Our results show that poachers respond to levels of enforcement and the severity of the penalty, rather than policies that attempt to influence the price of rhino horn.

\section{Discussion}

This article aims to achieve two objectives. The first is that to estimate the values of unknown and difficult to obtain parameters in the open-access harvesting literature. For example, it estimates the intrinsic growth rate of rhino populations in South Africa, as well as the adjustment parameter $n^{\prime}$. The model obtains these values in a novel fashion. First, a system dynamics model is developed and then optimisation is used to adjust the parameters until the best fit with the historical data is achieved. This 
method was also employed by Crookes (2016) for abalone stocks. Second, the model uses these estimates in order to determine under what conditions rhino populations may persist. This is undertaken by varying a number of enforcement parameters, costs, price, the probability of detection prior to a poaching event, and the magnitude of the fine. In this study only policies that directly affect poachers are considered. Market level interventions are considered elsewhere (see e.g. Crookes and Blignaut 2015).

As far as the parameter estimates are concerned, the adjustment parameter $n^{\prime}$, which measures changes in effort in response to rhino abundance, is relatively inelastic. This means that poachers will continue to hunt rhinos even if levels of abundance change dramatically. Poachers, therefore, are not motivated by the need for conserving rhinos. This is a novel finding since very little has been reported on the motives of poachers. Most research considers the motives of market participants. This has implications for rhino management as the education of poachers regarding the conservation value of the species may be beneficial in changing perceptions. The implication of this low elasticity of the adjustment parameter is that effort will fall with declines in rhino populations, but would be insufficient to prevent local extinctions of rhino populations namely the South African sub-species. This model, therefore, supports the findings of Di Minin et al. (2015) and Crookes and Blignaut (2015) that under current conditions rhino populations will be extinct over the next 20 years. One reason for this (from the model) is that rhino growth rates are on the lower end of the literature range estimates. The model is used to identify policy variables that are suitable for assessing conditions in which rhino populations are sustainable. Ling and Milner-Gulland (2008) develop a suite of measures for assessing the sustainability of wildlife populations. This article extends their analysis to include not only Beckerian enforcement measures such as probability of detection and magnitude of fine as sustainability criteria, but also profitability measures such as cost and price parameters.

We find that influencing the probability of detection and conviction prior to a poaching event produces equilibrium conditions favourable for regulating poaching behaviour. This is similar to the findings of De Minin et al. (2015). Even if we assume that market price reduction measures had a commensurate effect on the supply chain, resulting in the reduction of the rhino horn price for poachers, we find that reducing the price of rhino horn as a standalone policy would not be effective in curbing rhino poaching. Price would have to be very low, and poacher costs also increased, for this policy to be effective. In reality, influencing poacher costs is a difficult variable to manage on a macro level, and is therefore not regarded as an appropriate management intervention. The results from the BBN model corroborate these findings. Even under parameter uncertainty, on-the-ground management through patrolling and enforcement as well as levying a higher magnitude of fines, are more effective than price reduction strategies. This finding is important, given the recent South African legal judgement to lift the 'domestic' trade ban, effectively giving poachers a de jure means to sell rhino horn.

This article proposes that the probability of detection and conviction prior to a poaching event $(b)$ is used as a tool for managing rhino populations. Crookes (2016) found that, if there is a legitimate trade, there is an incentive for wildlife management authorities to increase the probability of detection after a poaching event in order to maximise the revenues from selling wildlife products on the legal market. This results in a "trading on extinction" effect, with high revenues for authorities in the short term, 
but the non-persistence of the traded species over the longer term. We find that "command and control" measures that prevent poaching are the likely to be the most effective management measure. The data show that this approach does appear to be working, with numbers of rhinos poached falling since 2014. In 2016 1,054 rhinos were poached in South Africa, in 2015, this was 1,175, compared with 1,215 in 2014.

\section{Acknowledgements}

The study is a result of a three year research program investigating novel approaches for endangered species modelling. The author gratefully acknowledges comments from Prof. E.J. Milner-Gulland and Prof. James Blignaut. Editorial assistance was provided by Ms Leandri van der Elst of ASSET Research. Funding from the National Research Foundation and DEA: NRM is gratefully acknowledged. The author also thanks SAEON for hosting the project in its latter stages.

\section{References}

Ball, P. 2015. Material witness: The complex costs of faking it. Nature materials, 14(7):660.

Barlas Y., 1996. Formal aspects of model validity and validation in system dynamics. System Dynamics Review 12(3): 183-210.

Becker, G.S. 1968. Crime and Punishment: An Economic Approach. Journal of Political Economy, 76(2):169-217.

Bjørndal, T. \& Conrad, J.M. 1987. The Dynamics of an Open Access Fishery. Canadian Journal of Economics, 20:74-85.

Brander, J.A. \& Taylor, M.S. 1998. The simple economics of Easter Island: a Ricardo-Malthus model of renewable resource use. American Economic Review, 88(1):119-138.

Bulte, E.H. 2003. Open access harvesting of wildlife: the poaching pit and conservation of endangered species. Agric Econ, 28:27-37.

Bunnefeld, N., Hoshino, E. \& Milner-Gulland, E.J. 2011. Management strategy evaluation: a powerful tool for conservation? Trends in Ecology \& Evolution, 26(9):441-447.

Butterworth, D.S., Plagányi, É.E., Robinson, W.M.L, Moosa, N. \& De Moor, C.L. 2015. Penguin modelling approach queried. Ecological Modelling, 316:78-80.

Cain, J. 2011. Planning improvements in natural resource management. Guidelines for using Bayesian networks to support the planning and management of development programmes in the water sector and beyond. Crowmarsh Gifford, Wallingford: Centre for Ecology and Hydrology.

CITES. 2013a. Sixteenth meeting of the Conference of the Parties Bangkok (Thailand), 3-14 March 2013. CoP16 Inf. 51.

CITES. 2013b. Sixteenth meeting of the Conference of the Parties Bangkok (Thailand), 3-14 March 2013. CoP16 Doc. 54.2 (Rev. 1).

Collins, A., Cox, C. and Pamment, N. (2017). Culture, Conservation and Crime: Regulating Ivory Markets for Antiques and Crafts, Ecological Economics, 135, pp.186-194. 
Coyle, G. \& Exelby, D. 2000. The validation of commercial system dynamics models. System dynamics review, 16(1):27-41.f

Cromsigt, J.P.G.M., Hearne, J., Heitkonig, I.M.A. \& Prins, H.H.T. 2002. Using models in the management of Black rhino populations. Ecological modelling, 149:203-211.

Crookes, D.J. 2012. Modelling the ecological-economic impacts of restoring natural capital, with a special focus on water and agriculture, at eight sites in South Africa. Ph.D dissertation, University of Stellenbosch, Stellenbosch.

Crookes, D.J. 2016. Trading on extinction: an open access deterrence model for the South African abalone fishery. South African Journal of Science 112(3/4): 105-113.

Crookes, D.J. \& Blignaut, J.N. 2016. A categorisation and evaluation of rhino management policies. Development Southern Africa 33(4):459-469

Crookes D.J., Blignaut J.N., 2016. Predator-prey analysis using system dynamics: an application to the steel industry. South African Journal of Economic and Management Sciences 19 (5):733-746

Crookes D.J. \& Blignaut J.N. 2015. Debunking the myth that a legal trade will solve the rhino horn crisis: A system dynamics model for market demand. Journal for Nature Conservation, 28:11-18.

DEA, 2014. Rhino poaching statistics. Issued by the DEA on 28 May 2014. Department of Environmental Affairs, Pretoria.

Department of Environment Affairs. 2014. South African Government is aware that ongoing scourge of rhino poaching is linked to worldwide Illicit wildlife trade. Media release, 20 November.

De Wit M.P. \& Crookes D.J., 2013. Improved decision-making on irrigation farming in arid zones using a system dynamics model. South African Journal of Science 109 (11/12), 8 pages

Di Minin, E., Laitila, J., Montesino-Pouzols, F., Leader-Williams, N., Slotow, R., Goodman, P.S., Conway, A.J. \& Moilanen, A. 2015. Identification of Policies for a Sustainable Legal Trade in Rhinoceros Horn Based on Population Projection and Socioeconomic Models. Conservation Biology 29(2): 545-555.

Eberlein, R. L. and D. W. Peterson. 1994. Understanding Models with VENSIM. In Modeling for Learning Organizations, ed. J. D. W. Morecroft and J. D. Sterman. Portland, OR: Productivity Press.

Eustace, M., 2012. Rhino poaching: what is the solution? Business day 20 January 2012: 1-4

Ford, A. 1999. Modeling the Environment: An Introduction to System Dynamics Modeling of Environmental Systems. Washington D.C: Island Press.

Goebel, R., Sanfelice, R.G. \& Teel, A.R. 2009. Hybrid dynamical systems. IEEE Control Systems Magazine, 29(2):28-93.

Hall, R.J., Milner-Gulland, E.J. \& Chourchamp, F. 2008. Endangering the endangered: The effects of perceived rarity on species exploitation. Conservation Letters, 1:75-81.

Hall-Martin, A. 1986. Recruitment in a small black rhino population. Pachyderm, 7:6-7.

Hitchins, P.M. \& Anderson, J.L. 1983. Reproduction, population characteristics and management of the black rhinoceros in the Hluhluwe/Corridor/Umfolozi game reserve complex. S. Afr. J. Wildl. Res., 13:78-85.

Korb, K.B. \& Nicholson, A.E. 2010. Bayesian artificial intelligence. Boca Raton, Florida: CRC press. 
Larrosa, C., Carrasco, L.R. \& Milner-Gulland, E.J. 2016. Unintended Feedbacks: Challenges and Opportunities for Improving Conservation Effectiveness. Conservation Letters. doi: 10.1111/conl.12240.

Leclerc C., Bellard, C., Luque, G.M. \& Courchamp, F. 2015. Overcoming extinction: understanding processes of recovery of the Tibetan antelope. Ecosphere, 6(9):1-14.

Ling, S. \& Milner-Gulland, E.J. 2008. When does spatial structure matter in models of wildlife harvesting? Journal of Applied Ecology, 45:63-71.

Macleod, F. 2014. Kruger Park's sugar road to rhino hell. Mail and Guardian, 7 November. Available at: http://mg.co.za/article/2014-11-06-kruger-parks-sugar-road-to-rhino-hell/ (accessed on: 27 November 2014).

Markham, I. 2014. South Africa to evacuate up to 500 rhino from Kruger National Park. The Telegraph, 12 August.

Mazany, R.L., Charles, A.T. \& Cross, M.L. 1989. Fisheries regulation and the incentives to overfish. Paper at Canadian Economic Association meeting, Laval University, Quebec. 2-4 June.

Milner-Gulland, E.J. \& Leader-Williams, N. 1992. A model of incentives for the illegal exploitation of black rhinos and elephants: poaching pays in Luangwa Valley, Zambia. Journal of Applied Ecology, 29:388-401.

Millner-Gulland, E.J., 1993. An econometric analysis of consumer demand for ivory and rhino horn. Environmental Resource Economics 3, 73-95. Milner-Gulland, E. J. 1999. How many to dehorn? A model for decision-making by rhino managers. Animal Conservation, 2(2), 137-147.

Norsys Software Corp. 1997. Netica Application for Belief Networks and Influence Diagrams User's Guide Version 1.05 for Windows ${ }^{\circledR}$. Norsys Software Corp: Vancouver, BC, Canada

Opsomer, J. \& Conrad, J.M. 1994. An open-access analysis of northern anchovy fishery. Journal of environmental economics and management, 27:21-37.

Save the Rhino, 2013. Why are Kruger's rhinos being hit so hard? URL: http://www.savetherhino.org/latest_news/news/667_why_are_krugers_rhinos_being_hit_so_hard (accessed 27 November 2014).

Saysel, A.K. \& Barlas, Y. 2001. A dynamic model of salinization on irrigated lands. Ecological Modelling, 139(2):177-199.

Swart, J., Hearne, J.W. \& Goodman, P. 1990. A conservation model for black rhino. System Dynamics, 1:1128-1136.

Uehara, T. 2013. Ecological threshold and ecological economic threshold: Implications from an ecological economic model with adaptation. Ecological Economics, 93:374-384.

Venkat, K. 2005. Predator-Prey Dynamics and Wildlife Management: A System Dynamics Model. Surya Technologies, February 10.

Wilen, J.E. 1976. Common Property Resources and the Dynamics of Overexploitation: The Case of the North Pacific Fur Seal. University of British Columbia, Vancouver: Department of Economics, Working Paper No. 3. 